\title{
Age of red blood cells and mortality in the critically ill
}

\author{
Ville Pettilä ${ }^{1 *}$, Andrew J Westbrook ${ }^{1}$, Alistair D Nichol ${ }^{1,2}$, Michael J Bailey ${ }^{1}$, Erica M Wood ${ }^{3,4}$, Gillian Syres ${ }^{1}$, \\ Louise E Phillipss ${ }^{4}$, Alison Street ${ }^{5}$, Craig French ${ }^{6}$, Lynnette Murray ${ }^{1}$, Neil Orford ${ }^{7}$, John D Santamaria ${ }^{8}$, \\ Rinaldo Bellomo ${ }^{1}$, and David J Cooper ${ }^{1,2}$ for \\ the Blood Observational Study Investigators for the ANZICS Clinical Trials Group
}

\begin{abstract}
Introduction: In critically ill patients, it is uncertain whether exposure to older red blood cells (RBCs) may contribute to mortality. We therefore aimed to evaluate the association between the age of RBCs and outcome in a large unselected cohort of critically ill patients in Australia and New Zealand. We hypothesized that exposure to even a single unit of older RBCs may be associated with an increased risk of death.

Methods: We conducted a prospective, multicenter observational study in $47 \mathrm{ICUs}$ during a 5-week period between August 2008 and September 2008. We included 757 critically ill adult patients receiving at least one unit of RBCs. To test our hypothesis we compared hospital mortality according to quartiles of exposure to maximum age of RBCs without and with adjustment for possible confounding factors.

Results: Compared with other quartiles (mean maximum red cell age 22.7 days; mortality 121/568 (21.3\%)), patients treated with exposure to the lowest quartile of oldest RBCs (mean maximum red cell age 7.7 days; hospital mortality $25 / 189(13.2 \%))$ had an unadjusted absolute risk reduction in hospital mortality of $8.1 \%$ (95\% confidence interval $=2.2$ to $14.0 \%$ ). After adjustment for Acute Physiology and Chronic Health Evaluation III score, other blood component transfusions, number of RBC transfusions, pretransfusion hemoglobin concentration, and cardiac surgery, the odds ratio for hospital mortality for patients exposed to the older three quartiles compared with the lowest quartile was 2.01 (95\% confidence interval $=1.07$ to 3.77 ).
\end{abstract}

Conclusions: In critically ill patients, in Australia and New Zealand, exposure to older RBCs is independently associated with an increased risk of death.

\section{Introduction}

Anemia is extremely common in the critically ill [1] and is associated with poor outcomes [2-5]. It is therefore not surprising that 19 to $53 \%$ of all patients admitted to adult ICUs receive at least one unit of allogeneic red blood cells (RBCs) [1,6-8].

Several publications have highlighted that the administration of RBCs and the hemoglobin trigger used for the administration of RBCs may affect patient morbidity and mortality [9-18]. More recently, the age of RBCs has been the focus of concern as a potential cause of

\footnotetext{
* Correspondence: ville.pettila@hus.fi

'Australian and New Zealand Intensive Care Research Centre, Department of Epidemiology and Preventive Medicine, Monash University, Commercial

Road, Melbourne 3004, Victoria, Australia

Full list of author information is available at the end of the article
}

increased morbidity and mortality [10]. A recent review summarizing data from 27 different studies in adult patients, however, concluded that it is difficult to determine whether there is a relationship between the age of transfused RBCs and mortality [19].

The mechanism responsible for the possible adverse effects of RBCs may relate to the development of storage lesions over time. During storage, in a way that increases over time, important biochemical changes occur: a reduction in 2,3-diphosphoglycerate, hypocalcemia, cell lysis, release of free hemoglobin, changes in nitric oxide levels, alterations in $\mathrm{pH}[20,21]$, and increases in lipids [22], complement [23] and cytokines [24]. These changes are accompanied by increased membrane fragility, which can compromise microcirculatory flow and lead to increased
C Biomed Central

C 2011 Pettilä et al.; licensee BioMed Central Ltd. This is an open access article distributed under the terms of the Creative Commons Attribution License (http://creativecommons.org/licenses/by/2.0), which permits unrestricted use, distribution, and reproduction in any medium, provided the original work is properly cited 
red cell-endothelial cell interaction and inflammatory cytokine release $[20,21]$. Such changes, which serve as potential explanations for more unfavorable outcomes, may be particularly disadvantageous to critically ill patients with a higher mortality risk. In this group, indirect evidence has linked the transfusion of older RBCs with adverse clinical consequences [25]. Unfortunately, all such evidence has been retrospective and/or focused on specific patient groups. The robustness of the relationship between the age of RBCs and adverse clinical outcome is thus limited both in strength and generalizability. Yet if this link exists, the public health consequences are great, given that the transfusion of RBCs is a common treatment in the critically ill. Furthermore, exposure to even a single unit of older RBCs might be associated with unfavorable outcome independent of the effect of volume of transfused RBCs and other confounding factors.

Accordingly, we hypothesized that the maximum age of RBCs to which a critically ill patient had been exposed would have an independent relationship with hospital mortality. We tested this hypothesis by conducting a prospective multicenter observational study in a heterogeneous group of medical and surgical critically ill patients.

\section{Materials and methods Study design}

We performed a prospective multicenter observational study in Australian and New Zealand ICUs. All sites that were members of the Australian and New Zealand Intensive Care Society (ANZICS) Clinical Trials Group were invited to participate, and 47 centers agreed to collect data. Each center obtained local Institutional Ethics Committee approval. Informed consent was waived at all sites. Over a 5-week period (August to September 2008) all new adult patients admitted to the ICU who received RBCs were included. Patients remained in the study until hospital death or discharge.

Patient-specific data included the following: date and time of hospital and ICU admission, gender, age, Acute Physiology and Chronic Health Evaluation (APACHE) III diagnostic code and score, and pre-existing or currently active co-morbidities. Any type of blood component given within 24 hours prior to ICU admission or during the ICU stay was recorded. The date, time and patient status (alive or dead) at hospital discharge were also noted. RBC-specific data included the age of the RBC unit at the time of transfusion and the leukodepletion status. The age of the blood was determined by subtracting the date of collection from the date of transfusion. The donation number (this number is unique to each blood donation) for every unit transfused was noted: these numbers were used to gather information specific to each RBC unit from the Australian Red Cross Blood Service and the New Zealand Blood Service.

\section{Data management}

Data were collected using case report forms, which were completed at sites and then faxed to the study coordinating centre at the ANZIC Research Centre, Monash University, Melbourne, Australia. The case report forms were subsequently scanned to a database using an optical reader. After checking the data and repeated queries to the study sites, the missing data related to RBC transfusions constituted $<1 \%$.

\section{Statistical methods regarding analysis of age of RBCs Maximum age of RBCs}

The relationship between hospital mortality and maximum age of RBCs received was determined using logistic regression. We chose the maximum age of RBCs transfused as the independent variable to be tested because we reasoned that exposure to even a single transfusion of old RBCs may have a toxic effect and contribute to increased mortality. Furthermore, we reasoned that once exposure to red cells with storage lesions occurs, it may cause irreversible damage and influence morbidity and mortality. The association, if present, may therefore not be linear in nature. First, we tested the age of RBCs as a continuous variable. Second, according to the literature [26], the maximum age of RBCs was divided into quartiles to include a sufficient number of patients in each group, with the lowest quartile representing the freshest possible RBCs.

\section{Adjustment for confounding factors}

From a univariate analysis, a list of biologically plausible and statistically significant confounders were identified, including severity of illness (APACHE III score), leukodepletion status, pre-ICU transfusions, cardiac surgery, other transfused blood components, and pretransfusion hemoglobin concentration preceding the first transfusion. We further adjusted for clustering of study sites. The APACHE III scores were first obtained by linkage of the study database with the ANZICS Adult Patient Database and were available for 432 study patients. Second, multiple requests for the missing APACHE III scores were sent retrospectively to the study sites, ending up with 713 surviving patients (94.2\%) and 141 out of 146 patients who died (96.6\%) with an APACHE III score (compared with $<1 \%$ of missing values in other study data). Hospital discharge status was re-checked at the same time.

Finally, given a possible relationship between exposure to older blood and increased mortality, we sought to further explore this relationship. A series of binomial variables were created for each possible maximum age of blood ( $<2$ days, $<3$ days, and so forth), and a cumulative graph was plotted indicating the mortality rate for 
each binomial cut-off point. To visually show the relationship between mortality and the maximum age of red blood, we also provided a plot of the predicted risk of death (as derived from the multivariate logistic regression model) against the maximum age of RBCs, and a locally weighted nonparametric smoother (LOWESS) was fitted to the data. LOWESS fits simple models to localized subsets of the data to build up a function that describes the deterministic part of the variation in the data, point by point.

\section{Statistical analysis}

Statistical analysis was performed using SAS version 9.1 (SAS Institute Inc., Cary, NC, USA). Descriptive statistics were computed separately for all study variables for all study patients. Univariate analysis was performed using chi-square tests for equal proportions, Student $t$ tests for normally distributed outcomes and Wilcoxon rank-sum tests otherwise, with results reported as percentages $(n)$, means (standard errors), or medians (interquartile ranges). The results from logistic regression analysis were reported as odds ratios (ORs) (95\% confidence interval $(\mathrm{CI})$ ). Two-sided $P=0.05$ was considered statistically significant.

Multivariate logistic regression models were constructed using both stepwise selection and backward elimination procedures with statistically significant covariates $(P<0.05)$ remaining in the model. Models included the identified list of covariates firstly using the maximum age of blood as a continuous variable and then secondly as a predetermined categorical variable in quartiles. The final model was further assessed for goodness of fit (Hosmer-Lemeshow test), points of influence (standardized differences in parameter estimates due to deleting the corresponding observation) and clinical and biological plausibility. To ensure that the relationship between the maximum age of blood and mortality did not differ for specific subgroups, interactions between the age of RBCs and all other covariates were explored.

\section{Results}

\section{Patients and participating centers}

A total of 47 ICUs participated in the study (Australia, $n$ $=36$; New Zealand, $n=11$ ). All ICU types were represented: 28 tertiary ICUs, 10 metropolitan ICUs, four rural ICUs and five private ICUs.

In total, 757 patients received one or more units of RBCs. Their demographic and clinical data are shown in Table 1. According to their APACHE III diagnostic classification, $416(55.0 \%)$ were operative patients and 341 (45.0\%) were nonoperative patients. The largest diagnostic groups were cardiac surgery patients $(194,25.6 \%)$, bacterial pneumonia $(36,4.8 \%)$, septic shock or sepsis
(56, 7.3\%), gastrointestinal neoplasm $(23,3.0 \%)$, nonoperative gastrointestinal bleeding (21, 3.2\%), trauma (50, $6.6 \%)$, and operative gastrointestinal bleeding (15, 2.0\%). The number of transfusions and the age of RBCs are included in Table 1.

\section{Age of RBCs and hospital mortality}

The mean (median, standard error) pretransfusion hemoglobin level was $7.8(7.7,0.03) \mathrm{g} / \mathrm{dl}$. The ages of the oldest RBCs and unadjusted hospital mortalities for the quartiles of the whole study population $(n=757)$, and hospital mortalities for the quartiles of those included in the multivariate analysis $(n=713)$ according to maximum RBC age, are shown in Table 2. The hospital mortality in the lowest quartile (Quartile 1) was 25/ $189(13.2 \%)$ versus $121 / 568$ (21.3\%) in Quartiles 2 to 4, with a significant $(P=0.01)$ unadjusted absolute risk reduction of $8.1 \%$ ( $95 \% \mathrm{CI}=2.2$ to $14.0 \%)$ in hospital mortality.

\section{Adjustment for confounding factors}

In these 713 patients, there was no significant independent association with hospital mortality and the maximum age of RBCs as a continuous variable (univariate OR $1.02,95 \% \mathrm{CI}=1.003$ to $1.04, P=0.025$; multivariate $\mathrm{OR}=1.02,95 \% \mathrm{CI}=0.99$ to $1.04, P=0.15$ ), but there was a statistically significant difference in mortality between quartiles of maximum age of RBCs at both the univariate level $(P=0.01)$ and the multivariate level $(P$ $=0.03)$. Day 11 was the 25th percentile of the oldest RBC transfused (not the 25th percentile of all transfused $\mathrm{RBCs}$ ). When compared with the lowest quartile (Quartile 1), exposure to the combination of three quartiles (Quartiles 2 to 4) of maximum age of RBCs was associated with an increased risk of hospital mortality (adjusted $\mathrm{OR}=2.01,95 \% \mathrm{CI}=1.07$ to 3.77 ). Other variables independently associated with hospital mortality were APACHE III score, fresh frozen plasma transfusion, pretransfusion hemoglobin level, and cardiac surgery (for ORs see Table 3). The study site (clustering), leukodepletion status, number of RBC transfusions and pre-ICU transfusions (RBCs, platelets, fresh frozen plasma yes/no) did not show an independent association with hospital mortality.

The area under the curve for the multivariate model was 0.86 , and a Hosmer-Lemeshow $P=0.93$ suggested the model adequately fitted the data. A graphic trend for the adjusted hospital death according to the maximum age of RBCs is presented in Figure 1 for illustration. There were no significant interactions between the maximum age of blood and all other variables in the multivariate model. In addition, the predicted risk of death against the maximum age of RBCs with LOWESS is presented in Figure 2. 
Table 1 Patient characteristics $(n=757)$ and transfusion details

\begin{tabular}{|c|c|c|c|c|}
\hline & All patients & Quartile 1 & Quartiles 2 to 4 & $P$ value $^{\mathrm{a}}$ \\
\hline Age (years) & 66 (54 to 76$)$ & 65 (50 to 74$)$ & 66 (54 to 76$)$ & 0.16 \\
\hline Male & 468 (62\%) & $112(59 \%)$ & $356(62 \%)$ & 0.40 \\
\hline Cardiac surgery patients & $194(26 \%)$ & $51(26 \%)$ & $143(25 \%)$ & 0.62 \\
\hline Trauma patients & $50(7 \%)$ & $6(3 \%)$ & $44(7 \%)$ & 0.03 \\
\hline Sepsis patients & $56(7 \%)$ & $15(7 \%)$ & $41(7 \%)$ & 0.74 \\
\hline \multicolumn{5}{|l|}{ Received pre-ICU } \\
\hline $\mathrm{RBCS}$ & $333(44 \%)$ & $90(47 \%)$ & $243(42 \%)$ & 0.25 \\
\hline Platelets & $130(17 \%)$ & $33(17 \%)$ & $97(17 \%)$ & 0.90 \\
\hline FFP & $168(22 \%)$ & $48(25 \%)$ & $120(21 \%)$ & 0.22 \\
\hline RBCs transfused & $2(1$ to 4$)$ & 2 (2 to 3 ) & 2 (2 to 5$)$ & $<0.0001$ \\
\hline Average age of RBCs & $14(9.5$ to 21.5$)$ & 7.5 (5.7 to 9.0$)$ & 17.6 (12.9 to 24.0$)$ & $<0.0001$ \\
\hline Maximum age of RBCs & 18 (11 to 28$)$ & 8 (6 to 9) & 22 (15 to 30$)$ & $<0.0001$ \\
\hline RBCs leukodepleted & 599 (79\%) & $149(78 \%)$ & 450 (79\%) & 0.91 \\
\hline \multicolumn{5}{|l|}{ Pretransfusion } \\
\hline Hemoglobin (g/dl) & 7.7 (7.2 to 8.2$)$ & 7.6 (7.1 to 8.2$)$ & 7.7 (7.2 to 8.2$)$ & 0.50 \\
\hline Received platelets & $180(24 \%)$ & $48(25 \%)$ & $132(23 \%)$ & 0.55 \\
\hline Received FFP & $256(34 \%)$ & 57 (30\%) & 199 (35\%) & 0.22 \\
\hline ICU length of stay (days) & $3.9(1.9$ to 8.6$)$ & $3.5(1.7$ to 7.1$)$ & 4.2 (1.9 to 9.2$)$ & 0.02 \\
\hline Hospital mortality & $146(19.3 \%)$ & $25(13 \%)$ & $121(21 \%)$ & 0.015 \\
\hline
\end{tabular}

All values expressed as number (proportion) or median (interquartile range). RBC, red blood cell; FFP, fresh frozen plasma. ${ }^{a}$ Quartile 1 versus Quartiles 2 to 4.

\section{Discussion}

We conducted a prospective observational study in 47 ICUs in Australia and New Zealand to assess the association between age of RBCs and outcome. In critically ill patients receiving RBCs, we found an association between exposure to older red cells and increased hospital mortality rate. This association remained after adjustment for potential confounding factors.

In this study, the mean age of all RBCs was 16.2 days and the oldest RBC unit given to each patient was 19.6 days on average. This compares with 21.2 days in the United States [1] and 16.2 days in Europe [7]. In 2007, the mean calculated age of transfused RBCs in the United States was 19.5 days, although just $7.8 \%$ of the hospitals reported such data [27]. Our results, therefore, are in agreement with the mean age of RBCs in previous studies and in other countries.

Table 2 Unadjusted mortality rates according to quartiles of maximum age of red cells

\begin{tabular}{llll}
\hline Quartile & Age of RBCs (days) & \multicolumn{2}{c}{ Mortality } \\
\cline { 3 - 4 } & & All patients & APACHE III scored \\
\hline 1 & $7.7(2$ to 11$)$ & $25 / 189(13.2 \%)$ & $24 / 185(13.0 \%)$ \\
2 & $13.8(11$ to 18$)$ & $41 / 189(21.7 \%)$ & $40 / 175(22.9 \%)$ \\
3 & $22.6(18$ to 28$)$ & $36 / 189(19.1 \%)$ & $34 / 176(19.3 \%)$ \\
4 & $34.4(28$ to 42$)$ & $44 / 190(23.2 \%)$ & $43 / 177(24.3 \%)$ \\
2 to 4 & $22.7(11$ to 42$)$ & $121 / 568(21.3 \%)$ & $117 / 528(22.1 \%)$ \\
\hline
\end{tabular}

Values expressed as median (range) or number/total (proportion). RBC, red blood cell; APACHE, Acute Physiology and Chronic Health Evaluation.
The mean pretransfusion hemoglobin values in previous studies - namely $8.6 \mathrm{~g} / \mathrm{dl}$ in the United States [1] and $8.4 \mathrm{~g} / \mathrm{dl}$ in Europe [7] - are in line with our mean pretransfusion hemoglobin concentration. In a previous study in Australia and New Zealand conducted in 2001 by French and colleagues the median pretransfusion hemoglobin level was $8.2 \mathrm{~g} / \mathrm{dl}$ [6], compared with $7.7 \mathrm{~g} /$ $\mathrm{dl}$ in the present study. In keeping with published evidence [9], therefore, Australian and New Zealand transfusion practice appears to have moved toward a more restrictive approach during recent years.

There is no suitably powered randomized controlled trial of the effect of age of RBCs on mortality [28]. Moreover, with the exception of cardiac surgery patients, no prospective cohort study of adequate sample size has evaluated the possible association between RBC age and mortality in the critical care setting. In trauma patients, four small single-center cohort studies have suggested that exposure to older RBCs may be an independent risk factor for multiple organ dysfunction [29], increased infections [14], and increased ICU length of stay [30] and hospital length of stay [31], but none have assessed its link with mortality. Our prospective multicenter cohort study is therefore the first to assess the independent relationship between the age of RBCs and hospital mortality in a heterogeneous population of critically ill patients. Nonetheless, our findings must be seen in light of three recent large retrospective studies in cardiac surgery patients [10], in trauma patients [32], and in a registry of hospitalized patients [33]. 
Table 3 Univariate and multivariate logistic regression analysis in patients with APACHE III scores

\begin{tabular}{|c|c|c|c|c|}
\hline \multirow[t]{2}{*}{ Variable } & \multicolumn{2}{|c|}{ Unadjusted } & \multicolumn{2}{|c|}{ Multivariate } \\
\hline & Odds ratio $(95 \% \mathrm{Cl})$ & $P$ value & Odds ratio $(95 \% \mathrm{Cl})$ & $P$ value \\
\hline APACHE III score (one point) & $1.03(1.02$ to 1.04$)$ & $<0.0001^{*}$ & 1.04 (1.03 to 1.05$)$ & $<0.0001^{*}$ \\
\hline RBC units transfused (number) & 1.09 (1.05 to 1.13$)$ & $<0.0001^{*}$ & $1.02(0.97$ to 1.08$)$ & 0.45 \\
\hline Platelet transfusion (yes/no) & 1.79 (1.20 to 2.67$)$ & $0.005^{*}$ & 1.17 (0.58 to 2.34$)$ & 0.66 \\
\hline FFP transfusion (yes/no) & 2.10 (1.44 to 3.05$)$ & $0.0001^{*}$ & 1.98 (1.16 to 3.38$)$ & $0.01^{*}$ \\
\hline Cardiac surgery (yes/no) & 0.21 (0.11 to 0.39 ) & $<0.0001^{*}$ & 0.31 (0.14 to 0.71$)$ & $0.006^{*}$ \\
\hline Pretransfusion hemoglobin (per $\mathrm{g} / \mathrm{dl}$ ) & $1.02(1.00$ to 1.04$)$ & $0.04^{*}$ & $1.06(1.03$ to 1.09$)$ & $0.0001^{*}$ \\
\hline Older quartiles versus freshest quartile of maximum RBC age & 1.87 (1.17 to 2.99$)$ & $0.01^{*}$ & 2.01 (1.07 to 3.77 ) & $0.03^{*}$ \\
\hline Leukodepletion & $1.12(0.71$ to 1.77$)$ & 0.61 & $0.88(0.34$ to 2.24$)$ & 0.78 \\
\hline Study site & & 0.12 & & 0.30 \\
\hline
\end{tabular}

APACHE, Acute Physiology and Chronic Health Evaluation; $\mathrm{Cl}$, confidence interval; FFP, fresh frozen plasma; RBC, red blood cell. *Significant variable $(P<0.05)$.

In a study of 6,002 cardiac surgery patients, Koch and colleagues found that patients given older RBCs had an increase in unadjusted mortality, prolonged ventilation and increased sepsis, and that the transfusion of older RBCs was independently associated with an increased risk-adjusted rate of a composite of serious adverse events [10]. Although the findings of the above study are both important and provocative and the sample size was large, several features of its design made confirmatory studies desirable. First, the study was retrospective with all the inherent shortcomings of such a design. Second, the study focused only on cardiac surgery patients. Third, the study excluded more than $28 \%$ of patients because those patients received both fresh and older RBCs. Fourth, the study separated patients into two groups only according to the age of RBCs using an arbitrary 14-day cut-off point. Finally, the study did not adjust for baseline differences, age or number of units transfused before ICU treatment, and combined intraoperative and postoperative RBC transfusions $[26,34]$.

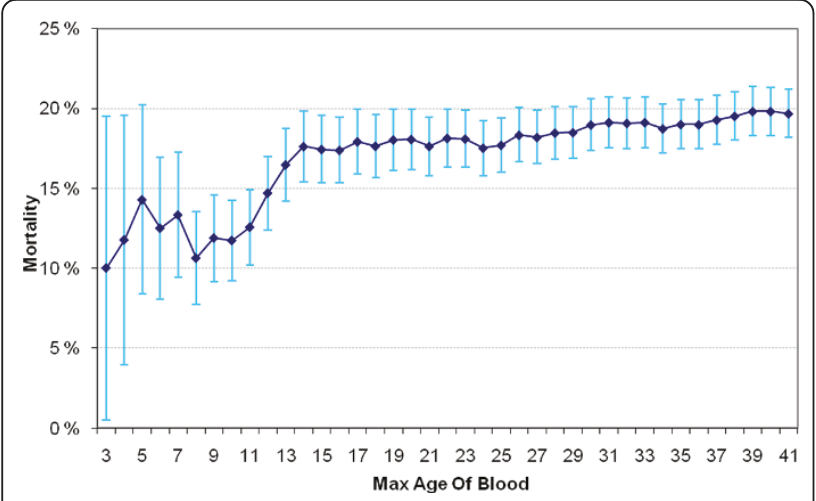

Figure 1 Hospital mortality according to maximum age of red blood cells. Hospital mortality (\%, 95\% confidence interval) according to the maximum age of red blood cells (RBCs) (days). Patients with the maximum age of RBCs exceeding each cut-off point are excluded.
Recently, Weinberg and colleagues demonstrated a higher mortality among trauma patients who received at least three RBC units [32]. In concordance, the largest registry study in recipients of $\mathrm{RBC}$ transfusion from 1995 to 2002 by Edgren and colleagues suggested that RBCs older than 30 days were associated with an increased risk of death in a 2-year follow-up [33].

Whilst impressive in sample size the retrospective registry studies have been performed mostly outside the critical care setting with a lower expected mortality rate and, thus, a lesser ability to detect relative reduction in risk. Therefore, because of the limitations of the previous studies and the public health importance of this issue, we considered it desirable to conduct a prospective, multicenter study to confirm or refute these findings in a broader population of critically ill patients.

We initially found a difference in unadjusted mortality rates according to the maximum age of red cells to which a patient had been exposed: the quartiles with older red cells were associated with a clear increase in mortality when compared with the lowest RBC quartile. However, we reasoned that this difference required correction for illness severity. Accordingly, to more rigorously test the validity of our findings, we performed multivariate analysis in these patients. We adjusted for both APACHE III score, number of transfusions, preICU transfusions, fresh frozen plasma and platelet transfusions, leukodepletion status, pretransfusion hemoglobin concentration, clustering of study sites, and cardiac surgery, and we used hospital mortality as the dependent variable and found a significant and independent association between the maximum age of red cells to which a patient had been exposed and mortality. Our findings indicating an association between exposure to older RBCs and increased mortality are in broad agreement with the results of the three large retrospective studies [10,32,33], and with a post hoc analysis of a randomized controlled trial in critically ill children by Gauvin and colleagues [35]. The association between higher 


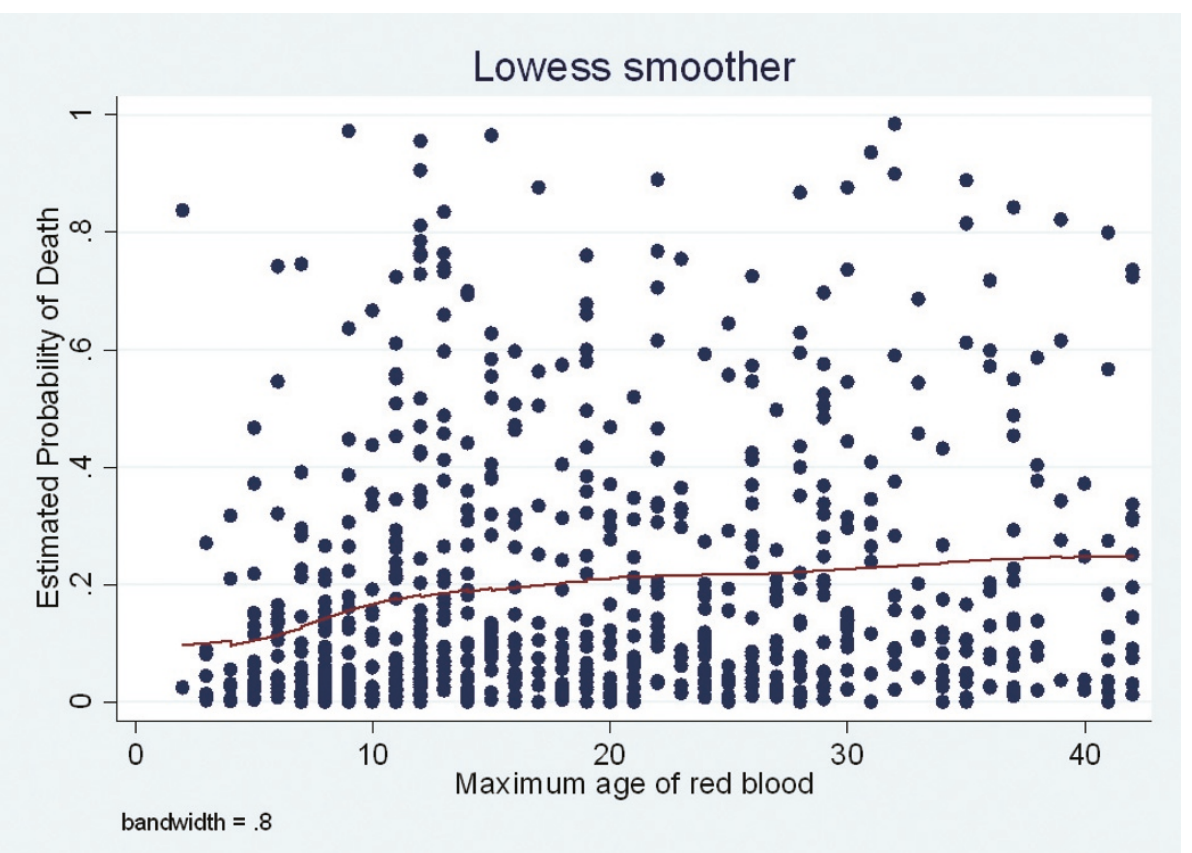

Figure 2 Predicted risk of death against maximum age of red blood cells. A locally weighted nonparametric smoother (LOWESS) for the predicted probability of death and the maximum age of red blood cells.

transfusion hemoglobin and higher mortality may reflect physician attempts to compensate for more severe underlying disease (for example, chronic pulmonary or cardiovascular or cerebrovascular disease) or ongoing bleeding.

The present study has several strengths. The investigation was a prospective, multicenter study and included a heterogeneous group of critically ill patients, increasing its generalizability. In addition, the study included multivariate adjustment for baseline characteristics, illness severity and relevant variables using in-hospital mortality as an endpoint.

The study also, however, has some significant limitations. This study was not a randomized trial, thus any association detected by multivariate regression analysis does not imply causation. For example, there may have been factors that influenced this association of which we are not aware and were unable to correct for (for example, use of vasopressors, $\mathrm{PaO}_{2} / \mathrm{FiO}_{2}$ ratios, use of antibiotics). Treating clinicians were not blinded to the age of RBCs. We have no reason to believe, however, that clinician behavior was influenced by or itself influenced the age of transfused RBCs, a variable outside their control. We did not obtain data on red cell transfusion outside the ICU. We did not follow-up patients after hospital discharge to establish their 90-day survival; such follow-up might have affected our findings. The study comprised only Australian and New Zealand ICUs and its findings may not apply to other healthcare systems. The transfusion practice and the mean age of transfused red cells, however, appear similar to those reported in studies from Europe and North America. The maximum age of red cells was not significantly associated with hospital mortality when evaluated as a continuous variable, but had a significant association when evaluated using quartiles, which can be explained by the nonlinear association demonstrated in Figure 1. In addition, our exploratory post hoc analysis suggests that a linear relationship between the age of blood and mortality may exist for RCBs with a lower maximum age ( $<15$ days old), but that, beyond approximately 15 days, the deleterious effects may be less. The missing linear relationship across the whole range of RBC's age is biologically plausible given the possibility of a maximum level of deleterious changes in RBCs over time. It is also conceivable that the use of a maximum value may not readily lend itself to a linear relationship. Finally, the unadjusted difference in hospital mortality was high, raising some uncertainty about biological plausibility. In response, we adjusted for all relevant available confounding factors, expecting the difference to lose statistical significance; it did not.

\section{Conclusions}

We conclude that, in critically ill patients in Australia and New Zealand who received RBCs, exposure to older $\mathrm{RBCs}$ is independently associated with increased hospital mortality compared with exposure to only the RBCs 
with the lowest quartile of maximum age. This observation now requires further investigation in other geographical and healthcare jurisdictions, and, if confirmed, justifies prospective randomized interventional studies to confirm or refute its impact on patient outcome.

\section{Key messages}

- Critically ill patients treated with RBCs of the lowest quartile of maximum age had an unadjusted absolute risk reduction in hospital mortality of $8.1 \%$ compared with the other quartiles.

- This relationship remained significant after adjustment for confounding factors $(\mathrm{OR}=2.01,95 \% \mathrm{CI}=$ 1.07 to 3.77 ).

- An adequately-sized multicentre randomized controlled trial focusing on the effect of age of RBCs and mortality in the critically ill is justified.

\section{Abbreviations}

ANZICS: Australian and New Zealand Intensive Care Society; APACHE: Acute Physiology and Chronic Health Evaluation; $\mathrm{Cl}$ : confidence interval; $\mathrm{FiO}_{2}$ : fraction of inspired oxygen; ICU: intensive care unit; LOWESS: Iocally weighted nonparametric smoother; OR: odds ratio; $\mathrm{PaO}_{2}$ : partial pressure of oxygen in arterial blood; RBC: red blood cell.

\section{Acknowledgements}

The authors would like to thank the Australian Red Cross Blood Service and the New Zealand Blood Service for excellent collaboration during this study, and the Australian and New Zealand Intensive Care Society Centre for Outcome and Resources Evaluation Adult Patient Database for the APACHE III data. Unrestricted grants were received from the Australian Red Cross Blood Service, and in-kind support from the Australian and New Zealand Intensive Care Research Centre.

The present study is a collaboration of the Australian and New Zealand Intensive Care Society Clinical Trials Group, the Australian Red Cross Blood Service, and the New Zealand Blood Service. The Blood Observational Study Writing Committee takes responsibility for the content and integrity of the present article.

Blood Observational Study Writing Committee: V. Pettilä (Chair), A. Westbrook (Chair), A. Nichol, M.J. Bailey, E. Wood, G. Syres, L.E. Phillips, A. Street, C. French, L. Murray, N. Orford, J. Santamaria, R. Bellomo, and D.J. Cooper.

The Blood Observational Study site investigators are as follows (alphabetical order - all in Australia unless specified): Alfred Hospital, Melbourne - D.J. Cooper, A. Nichol, A. Street, S. Vallance; Auckland City Hospital, Auckland, New Zealand - C. McArthur, S. McGuiness, L. Newby, C. Simmonds, R. Parke, H. Buhr; Austin Health, Melbourne - R. Bellomo, D. Goldsmith, K. O'Sullivan, I. Mercer; Ballarat Health Services, Ballarat - R. Gazzard, C. Tauschke, D. Hill; Bendigo Hospital, Bendigo - J. Fletcher, C. Boschert, G. Koch; Box Hill Hospital, Melbourne - D. Ernest, S. Eliott, B. Howe; Cabrini Private Hospital, Melbourne - F. Hawker; Calvary Mater Newcastle Hospital, Waratah - K. Ellem, K. Duff; Christchurch Hospital, Christchurch, New Zealand - S. Henderson, J. Mehrtens; Concord Hospital, Concord - D. Milliss, H. Wong; Dandenong Hospital, Dandenong - S. Arora, B O'Bree, K. Shepherd; Epworth Eastern, Melbourne - B. Ihle, S. Ho; Epworth Richmond, Melbourne - B. Ihle, M. Graan; Flinders Hospital, Bedford - A. Bernsten, E. Ryan. Frankston - J. Botha, J. Vuat; The Geelong Hospital, Geelong - N. Orford, A. Kinmonth, M. Fraser; Gold Coast Hospital, Southport - B. Richards, M. Tallott, R. Whitbread; Hawke's Bay Hospital, Hastings, New Zealand - R. Freebairn, A. Anderson; Liverpool Hospital, Liverpool - M. Parr, S. Micallef; Lyell McEwin, Elisabeth Vale - K. Deshpande, J. Wood; Middlemore Hospital, Auckland, New Zealand - T. Williams, J. Tai, A. Boase; Monash Medical Centre, Melbourne - S. Arora, P. Galt; Nelson Hospital, Nelson, New Zealand - B. King, R. Price, J. Tomlinson; Nepean Hospital, Penrith - L. Cole, I. Seppelt, L. Weisbrodt, R. Gresham, M. Nikas; North Shore Hospital, Auckland, New Zealand - J. Laing, J. Bell;
Palmerston North Hospital, Palmerston, New Zealand - G. McHugh, D. Hancock, S. Kirkman; Prince of Wales Hospital, Randwick - Y. Shehabi, M. Campbell, V. Stockdale; Queen Elisabeth Hospital, Adelaide - S. Peake, P. Williams; Royal Adelaide Hospital, Adelaide - P. Sharley, S. O'Connor; Royal Darwin Hospital, Darwin - D. Stephens, J. Thomas; Royal Hobart Hospital, Hobart - R. Sistla, R. McAllister, K. Marsden; Royal Melbourne Hospital, Melbourne - C. Maclsaac, D. Barge, T. Caf; Royal North Shore Hospital, Sydney - S. Finfer, L. Tan, S. Bird; Royal Perth Hospital, Perth - S. Webb, J. Chamberlain, G. McEntaggart, A. Gould; Royal Prince Alfred Hospital, Sydney - R. Totaro, D. Rajbhandari; Sir Charles Gairdner Hospital, Nedlands - S. Baker, B. Roberts; St Andrew's War Memorial Hospital, Brisbane - P. Lavercombe, R. Walker; St George Hospital, Sydney - J. Myburgh, V. Dhiacou; St Vincent's Hospital, Melbourne - J. Santamaria, R Smith, J. Holmes; St Vincent's, Sydney - P. Nair, C. Burns; Tauranga Hospital, Tauranga, New Zealand - T. Browne, J. Goodson; Waikato Hospital, Hamilton, New Zealand - F. van Haren, M. La Pine; Warringal Private, Heidelberg - G. Hart, J. Broadbent; Wellington Hospital, Wellington, New Zealand - P. Hicks, D. Mackle, L. Andrews; Western Hospital, Melbourne - C. French. H. Raunow, L. Keen; and Wollongong Hospital, Wollongong - A. Davey-Quinn, F. Hill, R. Xu.

\section{Author details}

${ }^{1}$ Australian and New Zealand Intensive Care Research Centre, Department of Epidemiology and Preventive Medicine, Monash University, Commercial Road, Melbourne 3004, Victoria, Australia. ${ }^{2}$ Department of Intensive Care and Hyperbaric Medicine, The Alfred Hospital, Commercial Road, Melbourne 3004, Victoria, Australia. ${ }^{3}$ Australian Red Cross Blood Service, St Kilda Road, Melbourne 3004, Victoria, Australia. ${ }^{4}$ Transfusion Outcomes Research Collaborative, Department of Epidemiology and Preventive Medicine, School of Public Health and Preventive Medicine, Monash University, Commercial Road, Melbourne 3004, Victoria, Australia. ${ }^{5}$ Haematology Unit, The Alfred Hospital, Commercial Road, Melbourne 3004, Victoria, Australia. ${ }^{6}$ Department of Intensive Care, Western Health, Gordon Street, Fitzroy 3011, Victoria, Australia. ${ }^{7}$ Department of Intensive Care, The Geelong Hospital, Ryrie Street, Geelong 3220, Victoria, Australia. ${ }^{8}$ Intensive Care Unit, St Vincent's Hospital, Victoria Parade, Fitzroy 3065, Victoria, Australia.

\section{Authors' contributions}

AJW, ADN, MJB, DJC, GS, EMW, AS, CF and RB were involved in the study design. GS, LM, AJW, ADN, JDS, NO and VP collected the data. MJB performed the statistical analysis. VP and RB drafted the first manuscript. All authors participated in drafting and revision of the manuscript. All authors were involved in data acquisition, and read and approved the final manuscript.

\section{Competing interests}

EMW is a full-time employee of the Australian Red Cross Blood Service. The other authors declare that they have no competing interests.

Received: 14 December 2010 Revised: 29 March 2011

Accepted: 15 April 2011 Published: 15 April 2011

\section{References}

1. Corwin HL, Gettinger A, Pearl RG, Fink MP, Levy MM, Abraham E, MacIntyre NR, Shabot MM, Duh MS, Shapiro MJ: The CRIT Study: anemia and blood transfusion in the critically ill - current clinical practice in the United States. Crit Care Med 2004, 32:39-52.

2. Carson JL, Duff A, Poses RM, Berlin JA, Spence RK, Trout R, Noveck H, Strom BL: Effect of anaemia and cardiovascular disease on surgical mortality and morbidity. Lancet 1996, 348:1055-1060.

3. Wu WC, Rathore SS, Wang Y, Radford MJ, Krumholz HM: Blood transfusion in elderly patients with acute myocardial infarction. N Engl J Med 2001, 345:1230-1236.

4. Carson JL, Noveck H, Berlin JA, Gould SA: Mortality and morbidity in patients with very low postoperative $\mathrm{Hb}$ levels who decline blood transfusion. Transfusion 2002, 42:812-818.

5. Lackritz EM, Campbell CC, Ruebush TK, Hightower AW, Wakube W, Steketee RW, Were JB: Effect of blood transfusion on survival among children in a Kenyan hospital. Lancet 1992, 340:524-528.

6. French CJ, Bellomo R, Finfer SR, Lipman J, Chapman M, Boyce NW: Appropriateness of red blood cell transfusion in Australasian intensive care practice. Med J Aust 2002, 177:548-551. 
7. Vincent $J L$, Baron JF, Reinhart K, Gattinoni L, Thijs L, Webb A, MeierHellmann A, Nollet G, Peres-Bota D: Anemia and blood transfusion in critically ill patients. JAMA 2002, 288:1499-1507.

8. Rao MP, Boralessa H, Morgan C, Soni N, Goldhill DR, Brett SJ, Boralessa H, Contreras M: Blood component use in critically ill patients. Anaesthesia 2002, 57:530-534.

9. Hebert PC, Wells G, Blajchman MA, Marshall J, Martin C, Pagliarello G, Tweeddale M, Schweitzer I, Yetisir E: A multicenter, randomized, controlled clinical trial of transfusion requirements in critical care. Transfusion Requirements in Critical Care Investigators, Canadian Critical Care Trials Group. N Engl J Med 1999, 340:409-417.

10. Koch CG, Li L, Sessler DI, Figueroa P, Hoeltge GA, Mihaljevic T, Blackstone EH: Duration of red-cell storage and complications after cardiac surgery. N Engl J Med 2008, 358:1229-1239.

11. Leal-Noval SR, Rincon-Ferrari MD, Garcia-Curiel A, Herruzo-Aviles A, Camacho-Larana P, Garnacho-Montero J, Amaya-Villar R: Transfusion of blood components and postoperative infection in patients undergoing cardiac surgery. Chest 2001, 119:1461-1468.

12. Purdy FR, Tweeddale MG, Merrick PM: Association of mortality with age of blood transfused in septic ICU patients. Can J Anaesth 1997, 44:1256-1261.

13. Vamvakas EC, Carven JH: Transfusion and postoperative pneumonia in coronary artery bypass graft surgery: effect of the length of storage of transfused red cells. Transfusion 1999, 39:701-710.

14. Offner PJ, Moore EE, Biffl WL, Johnson JL, Silliman CC: Increased rate of infection associated with transfusion of old blood after severe injury. Arch Surg 2002, 137:711-716, discussion 716-717.

15. Keller ME, Jean R, LaMorte WW, Millham F, Hirsch E: Effects of age of transfused blood on length of stay in trauma patients: a preliminary report. J Trauma 2002, 53:1023-1025.

16. Koch CG, Khandwala F, Li L, Estafanous FG, Loop FD, Blackstone EH: Persistent effect of red cell transfusion on health-related quality of life after cardiac surgery. Ann Thorac Surg 2006, 82:13-20.

17. Tran D, Cuesta M, Leeuwen PV, Nauta J, Wesdorp R: Risk factors for multiple organ system failure and death in critically injured patients. Surgery 1993, 114:21-30.

18. Moore F, Moore E, S A: Blood transfusion. An independent risk factor for postinjury multiple organ failure. Arch Surg 1997, 132:620-624.

19. Lelubre C, Piagnerelli M, Vincent $\mathrm{J}$ : Association between duration of storage of transfused red blood cells and morbidity and mortality in adult patients: myth or reality? Transfusion 2009, 49:1384-1394.

20. Card RT, Mohandas N, Mollison PL: Relationship of post-transfusion viability to deformability of stored red cells. Br J Haematol 1983 53:237-240.

21. Card RT, Mohandas N, Perkins HA, Shohet SB: Deformability of stored red blood cells. Relationship to degree of packing. Transfusion 1982, 22:96-101.

22. Silliman CC, Clay KL, Thurman GW, Johnson CA, Ambruso DR: Partial characterization of lipids that develop during the routine storage of blood and prime the neutrophil NADPH oxidase. J Lab Clin Med 1994, 124:684-694.

23. Hyllner M, Arnestad J, Bengtson J, Rydberg L, Bengtsson A: Complement activation during storage of whole blood, red cells, plasma, and buffy coat. Transfusion 1997, 37:264-268.

24. Shanwell A, Kristiansson M, Remberger M, Ringden O: Generation of cytokines in red cell concentrates during storage is prevented by prestorage white cell reduction. Transfusion 1997, 37:678-684.

25. Marik PE, Sibbald WJ: Effect of stored-blood transfusion on oxygen delivery in patients with sepsis. JAMA 1993, 269:3024-3029.

26. Dzik W: Fresh blood for everyone? Balancing availability and quality of stored RBCs. Transfus Med 2008, 18:260-265.

27. Facts about America's Blood Centers. [http://www.americasblood.org].

28. Hebert PC, Chin-Yee I, Fergusson D, Blajchman M, Martineau R, Clinch J, Olberg B: A pilot trial evaluating the clinical effects of prolonged storage of red cells. Anesth Analg 2005, 100:1433-1438, table of contents.

29. Zallen G, Offner PJ, Moore EE, Blackwell J, Ciesla DJ, Gabriel J, Denny C, Silliman CC: Age of transfused blood is an independent risk factor for postinjury multiple organ failure. Am J Surg 1999, 178:570-572.

30. Murrell Z, Haukoos JS, Putnam B, Klein SR: The effect of older blood on mortality, need for ICU care, and the length of ICU stay after major trauma. Am Surg 2005, 71:781-785.
31. Malone DL, Dunne J, Tracy JK, Putnam AT, Scalea TM, Napolitano LM: Blood transfusion, independent of shock severity, is associated with worse outcome in trauma. J Trauma 2003, 54:898-905, discussion 905-907.

32. Weinberg JA, MCGwin G Jr, Vandromme MJ, Marques MB, Melton SM, Reiff DA, Kerby JD, Rue LW: Duration of red cell storage influences mortality after trauma. J Trauma 2010, 69:1427-1431, discussion 1431-1432.

33. Edgren $G$, Kamper-Jorgensen M, Eloranta S, Rostgaard K, Custer B, Ullum H, Murphy EL, Busch MP, Reilly M, Melbye M, Hjalgrim H, Nyren O: Duration of red blood cell storage and survival of transfused patients (CME). Transfusion 2010, 50:1185-1195.

34. Benjamin RJ, Dodd RY: Red-cell storage and complications of cardiac surgery. N Engl J Med 2008, 358:2840-2841, author reply 2841-2842.

35. Gauvin F, Spinella PC, Lacroix J, Choker G, Ducruet T, Karam O, Hebert PC, Hutchison JS, Hume HA, Tucci M: Association between length of storage of transfused red blood cells and multiple organ dysfunction syndrome in pediatric intensive care patients. Transfusion 2010, 50:1902-1913.

doi:10.1186/cc10142

Cite this article as: Pettilä et al:: Age of red blood cells and mortality in the critically ill. Critical Care 2011 15:R116.

\section{Submit your next manuscript to BioMed Central and take full advantage of:}

- Convenient online submission

- Thorough peer review

- No space constraints or color figure charges

- Immediate publication on acceptance

- Inclusion in PubMed, CAS, Scopus and Google Scholar

- Research which is freely available for redistribution

Submit your manuscript at www.biomedcentral.com/submit
C) Biomed Central 